\title{
3-Min step test and treadmill exercise for evaluating exercise-induced asthma
}

\author{
G. Tancredi*, S. Quattrucci*, F. Scalercio*, G. De Castro\#, A.M. Zicari” , E. Bonci ${ }^{\top}$, S. Cingolani*, \\ L. Indinnimeo ${ }^{\#}$, F. Midulla*
}

3-Min step test and treadmill exercise for evaluating exercise-induced asthma. G. Tancredi, S. Quattrucci, F. Scalercio, G. De Castro, A.M. Zicari, E. Bonci, S. Cingolani, L. Indinnimeo, F. Midulla. (C) ERS Journals Ltd 2004.

ABSTRACT: A simple exercise test would be useful for detecting exercise-induced asthma, a common problem in asthmatic children. The current study compared the 3-min step test with treadmill exercise for evaluating exercise-induced asthma in asthmatic children and assessed whether responses to both tests are influenced by baseline lung function and habitual physical activity.

A series of 154 asthmatic children (84 male children; mean age $12.9 \pm 0.9$ yrs) underwent a 3-min step-test and treadmill testing on different days within a week at least $24 \mathrm{~h}$ apart. Before both tests each subject did spirometry to obtain the baseline forced expiratory volume in one second (FEV1). After both exercise challenges all subjects did serial spirometry and the lowest FEV1 recorded over time was used to calculate the fall in FEV1 expressed as a percentage of the measured pre-exercise (baseline) value (\% fall in $\mathrm{FEV} 1)$ and the area above the $\mathrm{FEV} 1$ curve $\left(\mathrm{AAC}_{0-30} \mathrm{~min}\right)$ expressed as a percentage of the pre-exercise value. Changes in both exercise variables were also analysed in percentile subgroups defined by questionnaire answers on habitual physical activity in hours.

The mean \% fall in FEV1 was significantly higher for treadmill exercise than for the step test (15.0 \pm 7.5 versus $11.7 \pm 5.9)$; and the $\mathrm{AAC}_{0-30}$ min was larger for treadmill than for the step test $(-261.6 \pm 139.9 \%$ versus $-197.3 \pm 105.0 \% \mathrm{~min})$. In all subgroups defined by habitual physical activity the mean \% fall in FEV1 decreased more after treadmill exercise than after the step test. After step test and treadmill exercise no significant correlation was found between \% fall in FEV1 and baseline lung function, or between \% fall in FEV1 among groups defined by habitual physical activity.

Although the 3-min step test yields a lower \% fall in forced expiratory volume in one second (FEV1) and a lower value of the area above the FEV1 curve than treadmill testing, it is a quick, economical, reproducible and portable alternative procedure for identifying exercise-induced asthma in outpatients and epidemiological studies. Baseline lung function and habitual physical activity have no influence on the amount or duration of exercise-induced asthma.

Eur Respir J 2004; 23: 569-574.
*Cystic Fibrosis Centre and ${ }^{\#}$ Allergology and Immunology, "Paediatric Dept, University of Rome "La Sapienza", Rome, Italy.

Correspondence: G. Tancredi

Paediatric Department

Cystic Fibrosis Centre

University of Rome "La Sapienza"

Viale Regina Elena, 324 - 00161 Rome

Italy

Fax: 39686323436

E-mail: giancarlo.tancredi@uniroma1.it

Keywords: Area above the curve $0-30$ min exercise-induced asthma

3-min step test

treadmill exercise test

Received: April 92003

Accepted after revision: November 172003
Although many asthmatic subjects find exercise-induced asthma (EIA) a problem, children and young adults suffer most from its effects because they engage more often in physical activities and sports.

The prevalence of bronchial asthma in children is around $10 \%$; and $40-90 \%$ of these patients have EIA [1, 2], a manifestation that is frequently undiagnosed [3]. Exercise challenge testing to evaluate EIA is helpful in the diagnosis and management of asthma and is also important in research studies investigating the efficacy of drug therapy.

EIA is defined as a condition in which physical activity triggers acute airway narrowing in people with heightened airway reactivity [4]. The diagnosis of EIA is suggested by the clinical history and demonstrated by a decrease of $15 \%$ in forced expiratory volume in one second (FEV1) after an exercise challenge, in accordance with the European Respiratory Society (ERS) and American Thoracic Society (ATS) statements [5, 6]. EIA is usually studied with various ergometers such as the treadmill and cycloergometer or free running. These tests are complex, expensive and require a large space. For this reason, a simple, standardised and reproducible challenge test is needed to assess the diagnosis of asthma and EIA. The step test, a reproducible test in healthy children and cystic fibrosis patients [7,8], is used with various protocols, to evaluate physical efficiency in healthy subjects and sportsmen [9-12]. It is legally compulsory in Italy for all persons wishing to engage in competitive sports [13]. The 3-min step test is also used to assess exercise capacity in children with cystic fibrosis $[8,14,15]$, to evaluate the effect of a course of intravenous antibiotics on exercise tolerance [16], to study candidates for lung transplantation [17], and to determine the risk of oxygen desaturation during exercise [18].

Few published studies have used the 3-min step test to assess EIA in asthmatic children [19-21]. In a study conducted in a small number of adolescent asthmatic patients, YounG and HoLsT [19] used a fall of $10 \%$ in the FEV1, whereas $15 \%$ is currently considered a better diagnostic value for EIA [5, 6]. In addition, FEINSTEIN et al. [20] studied only a selected 
population (adolescent African-American male football players); and conducted an epidemiological study without comparing the step test with treadmill exercise [21]. No published study has yet addressed the influence of baseline lung function and habitual physical activity on the presence or severity of EIA nor has EIA been evaluated with area above the curve between 0 and 30 minutes $\left(\mathrm{AAC}_{0-30 \mathrm{~min}}\right)$ after the 3-min step test.

The primary aim in this study was to confirm whether the 3-min step test effectively detected EIA, and to compare it with treadmill exercise in a group of asthmatic children, in view of future applications in outpatients and epidemiological studies. The study also investigated whether baseline lung function and habitual physical activity influence responses to the two exercise challenges.

\section{Methods}

\section{Patients}

One hundred and sixty-nine consecutive children attending the outpatients clinic at the Department of Paediatrics, University of Rome "La Sapienza", Italy, for respiratory disease during the 2 yrs from April 2000 to June 2002 were enrolled. Because all patients discontinued asthma medications before testing, to perform the challenge tests under safe conditions and in accordance with the ERS and ATS statements [5, 6] only subjects with a normal FEV1 $(\geqslant 80 \%$ of predicted) were studied. Of the 169 children enrolled, 154 subjects (84 male children, mean age 12.9 yrs, range: 10.1-14.8 yrs; 70 female children, mean age 13.1 yrs, range 10.5-14.6 yrs) entered the study and 15 were excluded: 11 who failed to complete both tests and four who had FEV1 values $<80 \%$ pred.

All participants had a clinical diagnosis of asthma confirmed by $a \geqslant 12 \%$ improvement in FEV1 after administration of inhaled salbutamol, according to the ATS guidelines 1994 [22]. The study was approved by the Hospital Research Ethics Committee and parents gave informed consent.

Each subject was evaluated in the Respiratory Pathophysiology Laboratory of the same Department. Children were tested between 9:00 to 12:00 $\mathrm{h}$ in a climate-controlled room (temperature around $21^{\circ} \mathrm{C}$, humidity around $45 \%$ ). None of the children had experienced acute episodes of asthma or respiratory tract infections, or both, in the previous 15 days and none had received oral or inhaled $\beta_{2}$-agonists, chromones or antihistaminics in the previous $48 \mathrm{~h}$. Oral and inhaled corticosteroids were withdrawn $24 \mathrm{~h}$ before testing because their anti-inflammatory effect may decrease bronchial responsiveness $[5,6]$.

\section{Study design}

During the first visit the study procedures were explained and a questionnaire was administered by a physician to each child and their parents. The questionnaire sought information on how children spent their time during the past week, to evaluate their hours of habitual physical activity [23, 24]. Four subgroups were defined by hours of physical activity (frequency and duration of their participation in organised sports or free but energetic play, or both): $0-2 \mathrm{~h} ; 3-5 \mathrm{~h} ; 6-9 \mathrm{~h}$; and $10-14 \mathrm{~h}$.

\section{Lung function tests}

Lung function was tested with an ultrasound flow-meter spirometer (Vmax 229; Sensor Medics Italia, Milan, Italy); the mass flow sensor was calibrated every day using a standard 3-L syringe taking into consideration room humidity, temperature and barometric pressure. Baseline (preexercise) variables considered were the largest forced vital capacity and FEV1 obtained from at least three spirometric tests.

\section{Exercise challenge}

Within a week after enrolment each subject did two exercise challenges in random order: a treadmill test (Runner, MTC Climb, Modena, Italy) and a step test. To avoid a possible refractory period after the first exercise challenge the two tests took place on different weekdays at least $24 \mathrm{~h}$ apart. Because the ATS [6] statement suggests that at least $4 \mathrm{~h}$ should elapse between repeat testing, instead of taking place in the afternoon, testing took place on the following morning. To avoid altered bronchial responsiveness, subjects who inhaled salbutamol after exercise owing to the onset of asthma were tested at least $24 \mathrm{~h}$ after the event. The incline and speed of the treadmill were administered according to a standardised protocol for 6-8 $\mathrm{min}$, to induce a heart rate $<80 \%$ of the maximum predicted ( 210 -age) during the last $4 \mathrm{~min}$ of the test [6]. Some children (14 of 154 children; 6 male), who were overweight and unfit, ran 6 min but maintained their target heart rate for only $1 \mathrm{~min}$. For the 3 -min step test, children stepped up and down a $30-\mathrm{cm}$ custom-made single step set at a rate of 30 steps per min for $3 \mathrm{~min}$, in time with an electronic metronome. For both tests nose clips were applied to ensure mouth breathing. The same observer evaluated the two tests in the same subject.

During both exercises a 3-lead electrocardiogram was recorded (Delta 3 plus; Cardioline Remco Italia, Milan, Italy) to determine heart rate and to detect eventual arrhythmias. Arterial oxygen saturation $\left(\mathrm{Sa}, \mathrm{O}_{2}\right)$ was monitored with a pulse oximeter (Nellcor $\mathbb{R}$; Hayward, CA, USA) through a probe attached to the index finger. After both tests, FEV1 was measured at least twice, at 1, 5, 10, 15, 20, and 30 mins after exercise and the lowest FEV1 recorded over this period was used to calculate the maximal percentage fall from baseline by the following equation:

\section{$\%$ fall in $\mathrm{FEV}_{1}=\left(\right.$ pre-exercise $\mathrm{FEV}_{1}-$}

lowest $\mathrm{FEV}_{1}$ post-exercise)/pre-exercise $\mathrm{FEV}_{1} \times 100$

Subjects who reached a $\%$ fall in FEV1 $\geqslant 15 \%$ were considered positive for EIA [5,6]. The area above the curve $\left(\mathrm{AAC}_{0-30 \mathrm{~min}}\right)$ was defined as the area above the FEV1, expressed as a percentage of the pre-exercise value, obtained up to $30 \mathrm{~min}$ post-exercise, calculated using linear trapezoidal integration $[25,26]$. If FEV1 exceeded baseline values, the area was subtracted from the $\mathrm{AAC}_{0-30}$ min measurement with a percentage change in FEV1. The $\mathrm{AAC}_{0-30 \text { min }}$ therefore provided a single number integrating the amount and duration of bronchoconstriction. At the end of the exercise challenge children who had FEV1 values $10 \%$ lower than baseline, received $200 \mu \mathrm{g}$ of inhaled salbutamol before they left the laboratory.

To assess reproducibility of the 3-min step test, 43 randomly selected children (25 male and 18 female) who had normal FEV1 ( $>80 \%$ pred) repeated a second step test on the following day.

\section{Statistical analysis}

All values are reported as mean \pm SD. Kendall's tau-b and the $\mathrm{K}$ statistic to measure agreement were used to determine 
the possible correlation between the two challenge tests in EIA groups. Paired t-tests were used to evaluate the statistical significance between the mean values for the two tests. An analysis of variance (ANOVA) was used to evaluate statistical difference between the mean values for each group. Correlations among variables were assessed with Pearson's $r$ or the Spearman's rank test as appropriate. Bland-Altman's plot [27] was also used to compare changes in the outcome measures for the two tests. The difference between the percentage change in $\%$ fall in FEV1 obtained by the two tests was plotted against their mean values. The mean difference between tests, and the limits of agreement (defined as 2 SD from the mean of the two tests) were also calculated. $p$-Values $<0.05$ were considered to indicate statistical significance.

\section{Results}

All adverse experiences during and after exercise challenges were transient and self-limited (cough, chest tightness, wheezing) and there were no clinically significant findings on physical examination or electrocardiogram. Of the 154 children enrolled, 18 inhaled $200 \mu \mathrm{g}$ of salbutamol $30 \mathrm{~min}$ after the end of the exercise challenge because their FEV1 values were $10 \%$ lower than baseline. In 12 of the 18 subjects cough or wheeze or both developed during or immediately after exercise but all these subjects became asymptomatic before leaving the laboratory. None of the subjects with a normal FEV1 after exercise had tight chest or wheezing after exercise.

Before and during the two tests, all subjects had normal $\mathrm{Sa}, \mathrm{O}_{2}$ values (range 96-100\%). The mean heart rate values reached at the end of exercise challenges were higher after treadmill testing than after the step test $(194.8 \pm 7.0$ versus $190.9 \pm 4.6$ beats per minute (bpm); $\mathrm{p}<0.0001$ by paired $\mathrm{t}$-test).

All 154 patients had FEV1 pre-exercise values $\geqslant 80 \%$ pred. Mean baseline pre-exercise FEV1 values were similar before both challenge tests (step test: $97.8 \pm 7.5$; treadmill 97.6 $\pm 5.2 \%$, $\mathrm{p}=\mathrm{NS}$ ).

In 85 of the 154 children studied $(55.2 \%)$ both tests induced EIA and in 55 children $(35.7 \%)$ both tests were negative. Of the remaining 14 children, 12 subjects had EIA after treadmill testing but not after the 3-min step test and only two subjects had EIA after the step test but not after treadmill exercise. Kendall tau-b correlation showed a significant relationship between the two tests (tau-b coefficient, 0.82; $\mathrm{p}<0.001$; table 1).

Data for the 43 children who had completed the second step test showed that the 3-min step test yielded reproducible data. On the two occasions no significant difference in maximal heart rate $\left(1^{\circ}\right.$ step test versus $2^{\circ}$ step test: $191.0 \pm 4.6$; $192.0 \pm 5.0 \mathrm{bpm}, \mathrm{p}=\mathrm{NS}$ by paired t-test $)$ and \% FEV1 fall $\left(1^{\circ}\right.$ step test versus $2^{\circ}$ step test: $12.8 \pm 5.9 ; 12.1 \pm 5.9 \%, \mathrm{p}=\mathrm{NS}$ by

Table 1.-The presence of exercise-induced asthma (EIA) after treadmill exercise and the 3-min step test in the 154 asthmatic children

\begin{tabular}{lccc}
\hline & \multicolumn{3}{c}{ Treadmill } \\
\cline { 2 - 4 } & EIA+ & EIA- & All subjects \\
\hline Step test & & & \\
EIA+ & 85 & 2 & $87(56.5 \%)$ \\
EIA- & 12 & 55 & $67(43.5 \%)$ \\
All subjects & $97(63 \%)$ & $57(37 \%)$ & 154 \\
\hline
\end{tabular}

Data are presented as number and percentage of subjects with exerciseinduced asthma (EIA+: \% fall in forced expiratory volume in one second $($ FEV1) $\geqslant 15$; EIA-: \% fall in FEV1 $<15$ ). paired t-test) was observed and Kendall tau-b correlation showed a significant relationship between the two tests (tau-b coefficient, $0.90 ; \mathrm{p}<0.0001)$. There was no significant difference in the number of subjects who had EIA in both tests: 25 of $43(58.1 \%)$ children in the first test and 24 of $43(55.8 \%)$ in the second. The Bland-Altman plot comparing changes in the outcome measures for the two step tests showed that the mean difference in \% fall in FEV1 were low between the two tests $(0.7 \pm 2.6 \%)$, with small limits agreement $(-4.5 \%$ and $+5.9 \%)$.

The 3-min step test yielded high diagnostic power in comparison with the treadmill test (sensitivity: 87.6\%; 95\% confidence intervals (CI): $83.0-92.7$ and specificity: $96.5 \%$; 95\% CI: 93.7-99.2) and good positive and negative predictive values $(97.7 \%$; 95\% CI: $93.0-99.5$ and $82.1 \%$; 95\% CI: 74.0-87.0).

No significant difference was found in baseline lung function, age, height or habitual physical activity between the 12 subjects (3 male children) with EIA induced only by the treadmill and the others. But their mean maximum heart rate values reached at the end of the step test were significantly lower than those of the other subjects (186.5 \pm 5.4 versus $190.9 \pm 4.6 \mathrm{bpm}, \mathrm{p}<0.002$ by unpaired t-test).

The $\%$ fall in FEV1 was greater after treadmill exercise than after the step test $(15.0 \pm 7.5$ versus $11.7 \pm 5.9 \% ; \mathrm{p}<0.001$ by paired t-test); and a significant relationship was found between the two tests (Pearson's $r=0.81 ; \mathrm{p}<0.001$ ).

After exercise testing, with the exception of the \% FEV1 of baseline (pre-exercise) values determined in the first minute, all values for this variable assessed at the other time points $(5$, $10,15,20$, and $30 \mathrm{~min}$ after testing) were significantly higher after treadmill exercise than after the 3-min step test. In both tests, the \% fall in FEV1 reached maximum at 5 min (fig. 1).

Treadmill testing yielded a significantly larger $\mathrm{AAC}_{0-30 \mathrm{~min}}$ than the step test $(-261.6 \pm 139.9 \%$ versus $-197.3 \pm 105.0 \% \mathrm{~min}$; $\mathrm{p}<0.001$ by paired t-test) (fig. 2).

For each group defined in percentiles of habitual physical activity the mean \% fall in FEV1 was significantly higher after treadmill testing than after the step test. Subjects with fewer hours of physical activity (0-2) had a higher \% fall in FEV1 after the treadmill test than after the step test. No significant difference was found in the \% fall in FEV1 mean values within the four physical activity groups for the step test $(\mathrm{p}<0.2)$ or treadmill test $(\mathrm{p}<0.09)$ (table 2). Nor did the baseline FEV1 ( $\%$ pred) value correlate significantly with degree of $\%$ fall in post-exercise FEV1 in either test (treadmill $\mathrm{r}=-0.03, \mathrm{p}=\mathrm{NS}$; step-test: $\mathrm{r}=0.14, \mathrm{p}=\mathrm{NS}$ ).

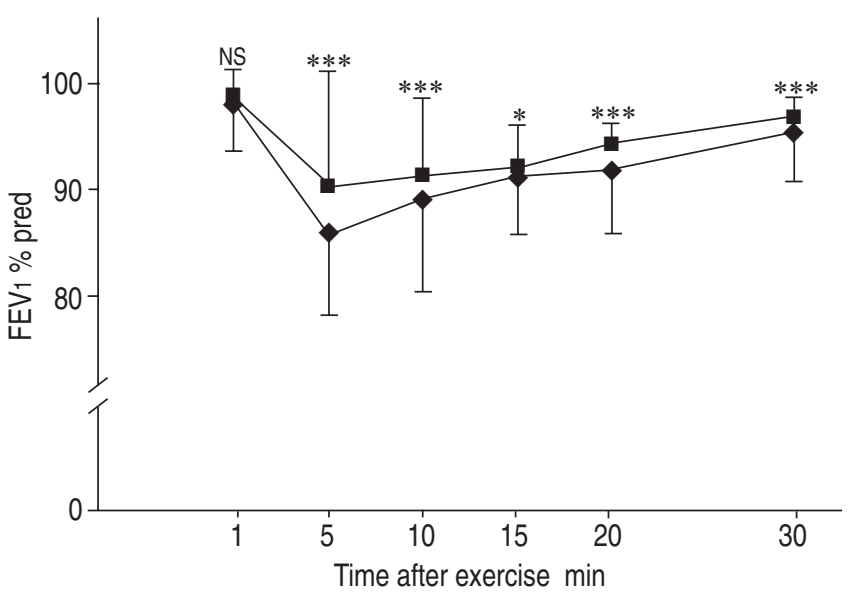

Fig. 1.-Forced expiratory volume in one second (FEV1) (\% pred) after the treadmill test $(\diamond)$ and the 3-min step test (ם). NS: nonsignificant; $*$ : $\mathrm{p}<0.05 ; * * *: \mathrm{p}<0.001$. 


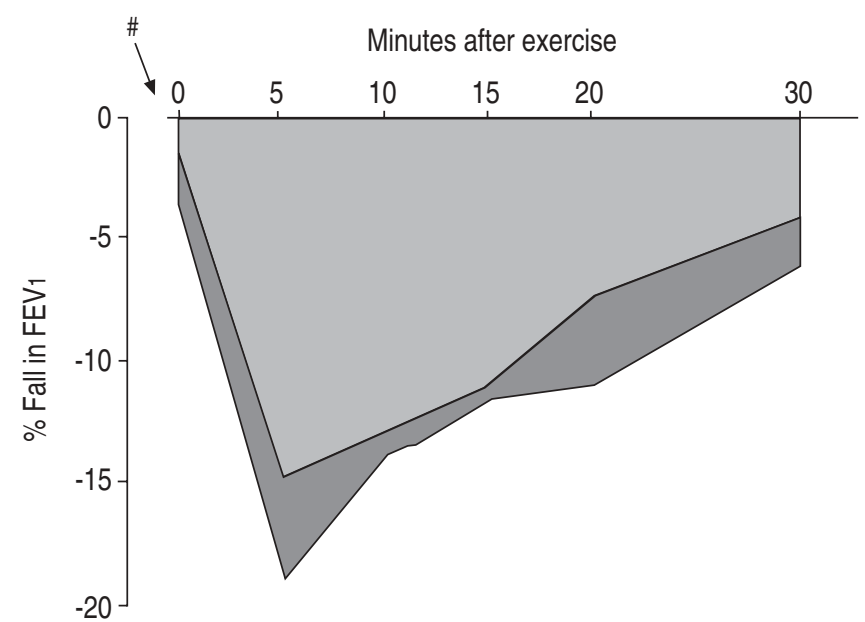

Fig. 2. - The area above the forced expiratory volume in one second (FEV1)-time curve from 0 to $30 \mathrm{~min}\left(\mathrm{AAC}_{0-30 \mathrm{~min}}\right)$ after exercise in the two tests. Treadmill ( $\square)$ : $-261.6 \pm 139.9 \%$ min; step test $(\square)$ : $-197.3 \pm 105.0 \%$ min $(p<0.001$ by paired $t$-test $){ }^{\#}$ : end of exercise.

The Bland-Altman plot comparing changes in the outcome measures for the two tests showed that the \% fall in FEV1 differed markedly between the two tests $(3.3 \pm 4.3 \%)$, with large limits of agreement $(-5.5 \%$ and $+12.1 \%)$ (fig. 3). In both tests, FEV1 decreased by a mean $13.3 \pm 6.4 \%$. In the group of subjects with a mean $\%$ fall in FEV1 of $>10 \%$, more subjects had a greater fall in FEV1 with the treadmill exercise test than with the 3 -min step test $(83 / 97,85.6 \%$ versus $14 / 97,14.4 \%)$.

\section{Discussion}

Although the 3-minute step test was quick and simple to perform in the asthmatic children that were studied, it was less effective than the treadmill test in detecting EIA $(97 / 154$ children versus 87/154), as confirmed by the significantly lower $\mathrm{AAC}_{0-30 \text { min }}$ (fig. 2) in the step test than in the treadmill test and the Bland-Altman plot (fig. 3). A possible reason why the two tests differed is that because the step test has a short duration, children reached and maintained a higher maximal heart rate after treadmill exercise than after the step test $(p<0.0001)$. Presumably for this reason, the 12 children in whom EIA developed after the treadmill test but not after the step test had a lower maximal heart rate after the step test than the whole study sample. In accordance with the literature, the current authors confirmed that EIA is effort dependent, hence reproducible results depend also on a standardised exercise load [28]. In the step test the intensity and duration of exercise is therefore predetermined $(3 \mathrm{~min})$, whereas the treadmill test lasts at least $6 \mathrm{~min}$ and therefore allows subjects to reach higher minute ventilation, one of the major causes of EIA.

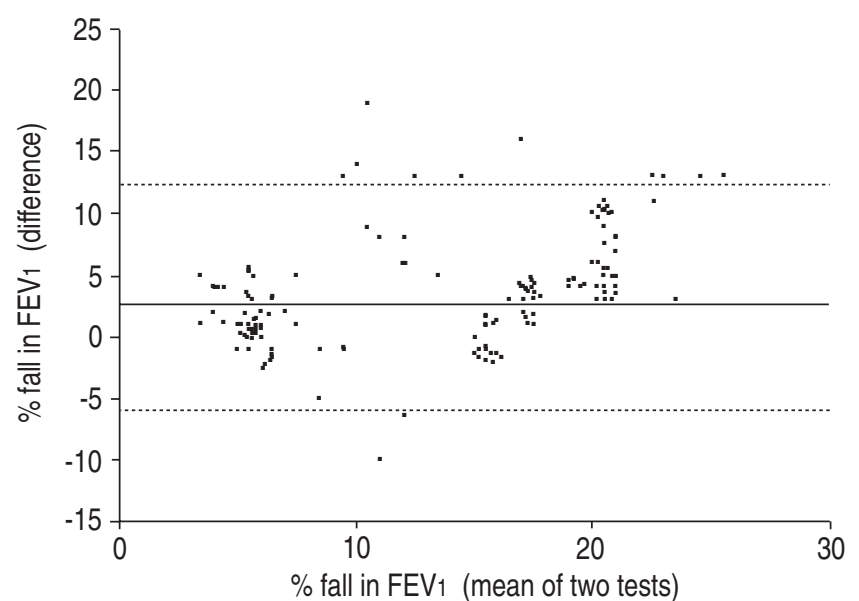

Fig. 3.-Bland-Altman plot of the percentage difference in the $\%$ fall in forced expiratory volume in one second (FEV1) between the two tests (treadmill minus step test) compared with their mean values. The mean difference of $\%$ fall in FEV1 is represented as an unbroken line. The limits of agreement (dashed lines) are defined as 2 SD from the mean difference of $\%$ fall in FEV1. Each point in the figure may represent one or more overlapping cases.

The 3-min step test nevertheless yielded high diagnostic power and good positive and negative predictive values in comparison with the treadmill test in detecting EIA in asthmatic children. A possible way of improving even further the diagnostic sensitivity of the 3-min step test is to increase its duration (5-6 min), to maintain the target heart rate $(80 \%$ pred) for longer. But this solution to the problem would mean foregoing one of the test's great advantages, its shortness. The target heart rate could also be increased and maintained by leaving the duration of the test unchanged and instead, raising the rate of stepping. Yet this solution has the disadvantage of making the step test more difficult to perform. As an alternative the current authors suggest increasing the height of the platform in relation to the children's height. This adjustment $(40-50 \mathrm{~cm})$ has already been recommended by the Italian law concerning step tests for adults wishing to begin competitive sports [13].

In the current study sample the 3-min step test also produced reproducible results, as others have reported [8]. Moreover, even if it decreases test sensitivity, performing exercise testing in a climate-controlled room, as in the current study, reduces variability related to temperature and humidity since cold air and dry ambient air (with low relative humidity, $\leqslant 50 \%$ ) increase airways hyperresponsiveness.

Although the findings of the current study suggest that the 3-min step test is less sensitive than treadmill testing in provoking EIA in asthmatic children (87/154 versus 97/154; table 1), when treadmill testing is unfeasible because of expense and complexity it may be used as an alternative to the exercise test. The free running test is also widely used as an

Table 2. - Study population grouped according to their habitual physical activity

\begin{tabular}{|c|c|c|c|c|}
\hline Habitual physical activity $h$ & No. of subjects & Treadmill $\%$ fall in FEV 1 & Step test $\%$ fall in FEV1 & p-value \\
\hline $0-2$ & 40 & $17.5 \pm 8.4$ & $11.3 \pm 6.1$ & $<0.001$ \\
\hline $3-5$ & 34 & $13.4 \pm 7.5$ & $10.2 \pm 6.0$ & $<0.001$ \\
\hline $6-9$ & 43 & $14.5 \pm 7.1$ & $12.0 \pm 6.0$ & $<0.001$ \\
\hline $10-14$ & 37 & $\begin{array}{c}14.3 \pm 6.8 \\
<0.09\end{array}$ & $\begin{array}{c}13.0 \pm 5.1 \\
<0.2^{\oplus}\end{array}$ & $<0.004$ \\
\hline
\end{tabular}

Data are presented as mean $\pm \mathrm{SD}$; p-values by paired t-test between two tests (treadmill or step test); ${ }^{\bullet}$ : an analysis of variance (ANOVA) was used to compare habitual physical activity in hours in the four groups for the same test (treadmill or step test). 
exercise test instead of the treadmill test in epidemiological studies. But it requires more space unless it takes place in an indoor gymnasium, is sometimes unavailable in outpatient or public settings and is not reproducible in the community setting [29]. Hence KUKAFKA et al. [30] assert that more data are needed on the effectiveness of free running as a "field test" in epidemiological studies in patients with asthma. Conversely, HABY et al. [31] consider a 6 min run on a $50-$ or $100-\mathrm{m}$ track on the flat to have good validity and reliability when performed under appropriate conditions (using noseclips to ensure mouth-breathing and monitoring heart rate to maintain a heart rate of $180 \pm 10 \mathrm{bpm}$ for the final $4 \mathrm{~min}$ of exercise). Hence they conclude that a 6-min free running challenge test could be used as a standardised tool in epidemiological studies.

Support for the 3-min step test as an alternative to the treadmill test comes from a study by FEINSTEIN et al. [20] who showed that the step test is more sensitive than physical examination, pre-exercise pulmonary function testing and self-administered questionnaire in identifying EIA in adolescent athletes and in elementary schoolchildren. In their study of 32 adolescent asthmatic patients, Young et al. [19] reported a fall of $>10 \%$ in FEV1 in 27 subjects after the treadmill test and in 25 after the step test. They also observed a strong correlation between the maximum \% fall in FEV1 after the two exercise challenges $(\mathrm{r}=0.92 ; \mathrm{p}<0.0001)$. In 11 patients, the patient's history of EIA agreed poorly with the asthmatic symptoms manifested after exercise testing.

Since 1982, the step test together with lung function testing and electrocardiogram before and during exertion has been compulsory in Italy for all persons wishing to engage in competitive sports [13]. The results of the current study now suggest that spirometric testing at 5 and $10 \mathrm{~min}$ after the 3-min step test, to identify a functionally important decrease in FEV1, would help in detecting unrecognised EIA. Accordingly, in the current authors' experience in an academic paediatric department, among 200 healthy children referred for exercise testing before engaging in sports activities, $>5 \%$ have EIA. International guidelines of asthma recommend that children with documented EIA should receive an adjunctive dose of inhaled $\beta_{2}$-agonists or chromones before starting physical activity [32]. Asthma has a high prevalence in European countries, about $10-12 \%$ of the childhood population. The prevalence of EIA is also much higher in subjects who take part in sport at elevated workloads in cold environments: ice hockey players $(21 \%)$ [33], cross country skiers $(31 \%)$ [34], and figure skaters $(55 \%)$ [35].

The present study also investigated whether baseline lung function influences responses to step test and treadmill exercise. In neither test did baseline FEV1 values, expressed as $\%$ pred, correlate either with the presence or the severity of EIA (\% fall in FEV1). All the children studied had baseline FEV1 values between $80-111 \%$ pred. In contrast, studying children with mild-to-moderate asthma LiNNA [36] observed a negative correlation between baseline flow values and the response to exercise. In another study CABRAL et al. [37] found that although the prevalence of EIA is greater in children with more severe asthma, the response to exercise can be absent even in children with severe persistent asthma. The intensity of the exercise-induced response is not consistently related to the clinical severity of asthma. CABRAL et al. [37] therefore concluded that the pre-exercise FEV1 predicts neither the severity of response nor the presence of EIA.

Another distinctive and partly unexpected finding from the current study is that the level of habitual physical activity was not related to the presence of EIA in either exercise test. Although in each of the four groups the \% fall in FEV1 was statistically higher for the treadmill test than for the step test, the mean \% fall in FEV1 did not differ statistically in subjects with higher or lower levels of habitual physical activity. All subjects, especially those who were less physically active $(0-2 \mathrm{~h})$ nevertheless had a higher $\%$ fall in FEV1 after treadmill testing than after the 3 -min step test $(17.5 \% \pm 8.4$ versus $11.3 \pm 6.1, \mathrm{p}<0.001$ by paired $\mathrm{t}$-test). Published reports suggest that the level of cardiorespiratory fitness has no influence on EIA [38]. In particular, normal cardiovascular fitness does not prevent EIA. Although physical training increases the aerobic capacity similarly in asthmatic patients and in healthy subjects, it has no detectable influence on the degree of EIA [39]. Conversely, a prolonged warm-up period of submaximal exercise can induce refractoriness of EIA without inducing bronchoconstriction [40, 41].

One of the prerequisites of an exercise challenge test is safety. None of the asthmatic patients had severe adverse events (persistent cough, wheezing or dyspnoea) after treadmill testing or the 3-min step test. The step test proved a safe and valid technique for evaluating the risk of oxygen desaturation in patients with chronic lung disease and a low lung diffusing capacity for carbon monoxide. In a series of 8,000 patients no complications (symptoms of cardiovascular collapse) developed, even though half the patients were elderly and therefore had a relatively high prevalence of cardiovascular disease. Other studies reported no major problems with step tests [18].

In conclusion, even if the step test causes a lower $\%$ fall in forced expiratory volume in one second than the treadmill test in asthmatic children, it is a quick, economical, reproducible, safe and portable alternative procedure that can be useful for identifying exercise-induced asthma or bronchial asthma in outpatients and epidemiological studies. Further studies are needed to standardise the step-test variables measured (for example the duration, the height of a single step and the rate of stepping).

\section{References}

1. Sterk PJ, Fabbri LM. Airway responsiveness: standardized challenge testing with pharmacological, physical and sensitizing stimuli in adults. Eur Respir J 1993; 6: 53-83.

2. Milgrom H, Taussig LM. Keeping children with exercise induced asthma active. Pediatrics 1999; 104: e38.

3. Hallstrand TS, Curtis JR, Koepsell TD, et al. Effectiveness of screening examinations to detect unrecognized exerciseinduced bronchoconstriction. J Pediatr 2002; 141: 343-348.

4. McFadden ER, Gilbert AI. Exercise-induced asthma. $N$ Engl J Med 1994; 330: 1362-1367.

5. ERS Task Force on Standardization of Clinical Exercise Testing. Clinical exercise testing with reference to lung diseases: indications, standardization and interpretation strategies. Eur Respir J 1997; 10: 2662-2289.

6. Crapo RO, Casaburi R, Coates AL, et al. Guidelines for methacholine and exercise challenge testing-1999. Official Statement of the American Thoracic Society. Am J Respir Crit Care Med 2000; 161: 309-329.

7. Tancredi G, Marolla F, Manganaro M, Mercuri M, Pagani M, Ronchetti R. The validity of the step test for the evaluation of fitness in children. Abstract of 8th Congress of SEP "European Society of Pneumology" Freiburg, September 10-14, 1989. Eur Respir J 1989; 8: 763s.

8. Balfour-Lynn IM, Prasad SA, Laverty A, Whitehead BF, Dinwiddie R. A step in the right direction: assessing exercise tolerance in cystic fibrosis. Pediatr Pulmonol 1998; 25: 278284.

9. Wassmer DJ, Mookerjee S. A descriptive profile of elite U.S. women's collegiate field hockey players. J Sports Med Phys Fitness 2002; 42: 165-171.

10. Craig CL, Russell SJ, Cameron C. Reliability and validity of 
Canada's physical activity monitor for assessing trends. Med Sci Sports Exerc 2002; 34: 1462-1467.

11. Burtscher M, Bachmann O, Hatzl T, et al. Cardiopulmonary and metabolic responses in healthy elderly humans during a 1-week hiking programme at high altitude. Eur $J$ Appl Physiol 2001; 84: 379-386.

12. Tammelin T, Nayha S, Rintamaki H, Zitting P. Occupational physical activity is related to physical fitness in young workers. Med Sci Sports Exerc 2002; 34: 158-165.

13. Legge Tutela Sanitaria Attività Sportive - D.M. 18-2-1982 modificata dal decreto del Ministro della Sanità 28 febbraio 1983 [Law for the health protection in sports activities ministerial decree February 18 1982, modified by the decree of the Minister of Health, February 28, 1983]. Gazzetta Ufficiale Repubblica Italiana del 15 marzo 1983, n. 72.

14. Narang I, Pike S, Rosenthal M, Balfour-Lynn IM, Bush A. Three-minute step test to assess exercise capacity in children with cystic fibrosis with mild lung disease. Pediatr Pulmonol 2003; 35: 108-113.

15. Prasad SA, Randall SD, Balfour-Lynn IM. Fifteen-count breathlessness score: an objective measure for children. Pediatr Pulmonol 2000; 30: 56-62.

16. Pike SE, Prasad SA, Balfour-Lynn IM. Effect of intravenous antibiotics on exercise tolerance (3-min step test) in cystic fibrosis. Pediatric Pulmonology 2001; 32: 38-43.

17. Aurora P, Prasad SA, Balfour-Lynn IM, Slade G, Whitehead B, Dinwiddie R. Exercise tolerance in children with cystic fibrosis undergoing lung transplantation assessment. Eur Respir J 2001; 18: 293-297.

18. Hadeli KO, Siegel EM, Sherrill DL, Beck KC, Enright PL. Predictors of oxygen desaturation during submaximal exercise in 8,000 patients. Chest 2001; 120: 88-92.

19. Young RP, Holst PE. A simple exercise test in assessment of asthma. N Z Med J. 1988; 101: 600-601.

20. Feinstein RA, LaRussa J, Wang-Dohlman A, Bartolucci AA. Screening adolescent athletes for exercise-induced asthma. Clin J Sport Med 1996; 6: 119-123.

21. Feinstein RA, Hains CS, Hemstreet MP, et al. A simple "step-test" protocol for identifying suspected unrecognized exercise-induced asthma (EIA) in children. Allergy Asthma Proc 1999; 20: 181-188.

22. Standardization of Spirometry, 1994 Update. American Thoracic Society. Am J Respir Crit Care Med 1995; 152: 1107-1136.

23. Bratteby LE, Samuelson G. A 7-day activity diary for assessment of daily energy expenditure validated by the doubly labelled water method in adolescents. Eur J Clin Nutr 1997; 51: 585-591.

24. Blair SN, Haskell WL, Ho P, et al. Assessment of habitual physical activity by a seven-day recall in a community survey and controlled experiments. Am J Epidemiol 1985; 122: 794 804.

25. Kemp JP, Dockhorn RJ, Shapiro GG, et al. Montelukast once daily inhibits exercise-induced bronchoconstriction in
6- to 14-year-old children with asthma. J Pediatr 1998; 133 $424-428$.

26. Dahlen B, O'Byrne PM, Watson RM, Roquet A, Larsen F, Inman $\mathrm{MD}$. The reproducibility and sample size requirements of exercise-induced bronchoconstriction measurements. Eur Respir J 2001; 17: 581-588.

27. Bland JM, Altman DG. Statistical methods for assessing agreement between two methods of clinical measurement. Lancet 1986; 1: 307-310.

28. Carlsen KH, Engh G, Mork M. Exercise-induced bronchoconstriction depends on exercise load. Respir Med 2000; 94: 750-755.

29. Powell CV, White RD, Primhak RA. Longitudinal study of free running exercise challenge: reproducibility. Arch Dis Child 1996; 74: 108-114.

30. Kukafka DS, Lang DM, Porter S, et al. Exercise-induced bronchospasm in high school athletes via a free running test. Incidence and epidemiology. Chest 1998; 114: 1613-1622.

31. Haby MM, Peat JK, Mellis CM, Anderson SD, Woolcock AJ. An exercise challenge for epidemiological studies of childhood asthma: validity and repeatability. Eur Respir $J$ 1995; 8: 729-736.

32. Global Initiative for Asthma (GINA) - updated April, 2002 www.ginasthma.com. Date updated: April 2002; Date accessed: April 2003.

33. Leuppi JD, Kuhn M, Comminot C, Reinhart WH. High prevalence of bronchial hyperresponsiveness and asthma in ice hockey players. Eur Respir J 1998; 12: 13-16.

34. Larsson K, Ohlsen P, Larsson L, Malmberg P, Rydstrom PO, Ulriksen $\mathrm{H}$. High prevalence of asthma in cross country skiers. Br Med J 1993; 307: 1326-1329.

35. Mannix ET, Farber MO, Palange P, Galassetti P, Manfredi F. Exercise-induced asthma in figure skaters. Chest 1996; 109: 312-5.

36. Linna $O$. Influence of baseline lung function on exerciseinduced response in childhood asthma. Acta Pediatr Scand 1990; 79: 664-669.

37. Cabral ALB, Conceicao GM, Fonceca-Guedes CHF, Martins MA. Exercise-induced bronchospasm in children. effects of asthma severity. Am J Respir Crit Care Med 1999; 159: 1819-1823.

38. Thio BJ, Nagelkerke AF, Ketel AG, et al. Exercise-induced asthma and cardiovascular fitness in asthmatic children. Thorax 1996; 51: 207-209.

39. McKenzie DC, McLuckie SL, Stirling DR. The protective effects of continuous and interval exercise in athletes with exercise-induced asthma. Med Sci Sports Exerc 1994; 26: 951-956.

40. de Bisschop C, Guenard H, Desnot P, Vergeret J. Reduction of exercise-induced asthma in children by short, repeated warm ups. Br J Sports Med 1999; 33: 100-104.

41. Reiff DB, Choudry NB, Pride NB, Ind PW. The effect of prolonged submaximal warm-up exercise on exerciseinduced asthma. Am Rev Respir Dis 1989; 139: 479-484. 